\title{
Síndrome hemofagocítica como diagnóstico diferencial na unidade de emergência
}

\author{
Acadêmicas: Francini Rossetto de Oliveira, Heloisa Souza Del Frari \\ Orientadores: Antonio Adolfo Guerra Soares Brandão, Luís Alberto de Paula Covas Lage
}

Síndrome hemofagocítica é uma patologia caracterizada por hiperativação do sistema imune, marcada por sinais e sintomas decorrentes de intensa inflamação sistêmica. Essa síndrome está associada a predisposição à imunodeficiência, bem como a presença de ativação imune exacerbada ou de uma resposta imune patológica.

O quadro clínico-laboratorial engloba função reduzida ou ausente das células NK, febre, esplenomegalia e/ou hepatomegalia, elevação da ferritina (ou do sCD25 - cadeia alfa do receptor de IL-2), citopenias variadas, redução do fibrinogênio, elevação de triglicérides, figuras de hemofagocitose em biópsia de tecido do sistema retículo-endotelial ou de aspirado/ biópsia de medula óssea, além de hepatite e acometimento do sistema nervoso central.

Em sua forma primária é uma síndrome predominantemente pediátrica (cuja apresentação congênita é a linfohistiocitose hemofagocítica hereditária), porém pode ser diagnosticada em todas as faixas etárias, até os 70 anos ${ }^{1}$, em sua forma secundária, com ligeiro predomínio no sexo masculino².

Etiologicamente, a síndrome hemofagocítica secundária associa-se a algumas patologias, tais como infecções (especialmente virais ${ }^{3}$ ), malignidades, doenças reumatológicas e imunodeficiências. No caso das malignidades, destacam-se as de origem linfoide T e NK, como o linfoma anaplásico de grandes células e leucemias ${ }^{2}$. Outros tumores hematológicos e tumores sólidos ${ }^{4}$ também são mais raramente associadas a esta condição.

No presente relato discutiremos detalhes de um caso de um paciente masculino de 74 anos, previamente hígido, admitido no pronto socorro do HC/FMUSP com queixa de febre diária de $39^{\circ} \mathrm{C}$ há 2 meses, associada a emagrecimento de aproximadamente $15 \mathrm{~kg}$, sudorese noturna, astenia e fraqueza. O exame físico inicial demonstrava pequenas linfonodomegalias cervicais e baço percutível, com quadro laboratorial marcado por bicitopenia - anemia e plaquetopenia - hiperferritinemia e hipertrigliceridemia, bem como elevação importante de PCR e VHS.

$\mathrm{Na}$ investigação do quadro, mielograma mostrou medula óssea com aumento da atividade macrofágica e figuras de hemofagocitose. O paciente evoluiu com melhora clínica inicial após tratamento com dexametasona e imunoglobulina. Devido à persistência de adenomegalias, realizado PET-CT que mostrou acentuado aumento do metabolismo glicolítico em diversas cadeias linfonodais. Mediante tal achado, realizado biópsia e exame anátomo-patológico de linfonodo paraaórtico à esquerda que evidenciou neoplasia maligna indiferenciada com padrão imunohistoquímico compatível com Linfoma Difuso de Grandes Células B.

A discussão de tal caso abordará aspectos importantes para o diagnóstico da Síndrome Hemofagocítica, que, devido a achados poucos específicos, baixa incidência e apresentação polimórfica, constitui-se em um diagnóstico desafiador para o médico generalista. O reconhecimento precoce dessa rara patologia é muito importante, uma vez que está associada a condições de base de alta gravidade, nas quais intervenções terapêuticas precoces são fundamentais para um desfecho clínico favorável.

Referências

1. Clementi R, Emmi L, Maccario R, Liotta F, Moretta L, Danesino C, Aricó M. Adult onset and atypical presentation of hemophagocytic lymphohistiocytosis in siblings carrying PRF1 mutations. Blood. 2002;100(6):2266-7.

2. Fallini B, Pileri S, De Solas I, Martelli MF, Mason DY, Delsol G, Gatter KC, Fagiolo M. Peripheral T-cell lymphoma associated with hemophagocytic syndrome. Blood. 1990;75(2):434-44.

3. Otrock ZK, Eby CS. Clinical characteristics, prognostic factors, and outcomes of adult patients with hemophagocytic lymphohistiocytosis. Am J Hematol. 2015;90(3):220-4.

4. Miyahara M, Sano M, Shibata K, Matsuzaki M, Ibaraki K, Shimamoto Y, Tokunaga O. B-cell lymphoma associated hemophagocytic syndrome: clinicopathological charatcteristics. Ann Hematol. 2000;79(7):378-88. 